effective use and or recognition of Occupational Health in the multi-disciplinary approach was much needed.

Method A scoping review of over 50 literature resources published since 2012 was conducted. The focus was on the evolvement and/or impact of historic milestones, legal frameworks, stakeholder involvement, and awareness strategies in RSA as compared between the disciplines of Occupational Health, Safety and Environment. The literature sources predominated around level 7 evidence. These were current legislation, standards, journal articles, professional association guidelines, professional newsletters, news and media feeds. A content analysis was conducted and tabularised for comparison.

Results Although health appeared to be a common thread, it was frequently coupled with safety and/or the environment resulting in a diluted picture with health in the background. The volumes of legislation, standards and guidelines for safety and the environment far outweighed Occupational Health. Implementation focused on safety and/or environmental strategies rather than health which was not decentralised to the district level such as environmental that had municipality bylaws, neither was it broken down into tangible levels for society and communities. Occupational Health in RSA hospitals still remains a huge concern. Small to medium business enterprises were overlooked and currently still pose as one of the challenges.

Discussion Increased involvement by the OHPs is strongly needed in government decision and policy making processes to cover the gaps. Occupational Health needs commitment, implementation, evaluation, support and penalties of non-compliance by stakeholders, government and labour.

\section{RISK OF STAPHYLOCOCCUS AUREUS EXPOSURE AMONG WORKERS IN SELECTED CATTLE AND SMALL RUMINANTS SLAUGHTERHOUSES IN TANZANIA}

${ }^{1}$ JS Mlimbila*, ${ }^{1} \mathrm{~S}$ Mamuya, ${ }^{1} \mathrm{~V}$ Ngowi, ${ }^{2} \mathrm{BE}$ Moen. ${ }^{1}$ Muhimbili University of Health and Allied Sciences, Dar es Salaam, Tanzania; ${ }^{2}$ Centre for International Health, University of Bergen

\subsection{6/oemed-2018-ICOHabstracts.833}

Introduction The occupations involving working with animal production have for so long been known to bring significant health risks to workers, with distinctive attention to injuries. However, workers employed at slaughterhouses are at risk of pathogen exposure and especially zoonotic ones due to general working condition that exposes them directly to live animals, carcasses and viscera of possibly infected animals. The increased use and misuse of antimicrobials in animal treatments and feed to promote growth have increased the development of antimicrobial resistance, exposing workers to a more serious infection. This study aimed to determine the prevalence of nasal antibiotic resistant Staphylococcus aureus and associated risk factors.

Methods A cross-sectional study was conducted to collect data using questionnaire for information on occupational and personal history, checklist for working conditions and nasal swabs from 427 workers at slaughterhouses in Dar es Salaam, Dodoma and Arusha regions in Tanzania. Swabs were tested for S.aureus and later isolates were screened for antibiotic susceptibility.

Results Overall prevalence of $S$. aureus nasal carriage was about $30.0 \%$ where as $5 \%$ was resistant to antibiotic. The prevalence was higher in slaughter or carcass processing workers but also about 5 times higher in cleaning. Many slaughterhouses had poor infrastructure, less than $60 \%$ had a toilet and less than $20 \%$ had hand-washing facilities. Slaughtering of sick animals was observed in about $10 \%$ of slaughterhouses. Less than half of workers wore personal protective clothing

Conclusion Working conditions of majority of cattle slaughterhouses visited in Tanzania are not in line with the health and safety recommendations. Current facilities and practices may increase occupational exposure to biological hazards. Cattle slaughterhouse workers may have increased exposure to livestock-associated $S$. aureus, particularly MRSA. Therefore, further epidemiologic investigation on occupational exposure to livestock-associated $S$. aureus is required.

\section{OCCUPATIONAL PHYSICAL INJURIES AMONG WORKERS IN ONSHORE OIL DRILLING OPERATIONS IN TURKANA COUNTY, KENYA}

${ }^{1} \mathrm{CO}$ Kamol*, ${ }^{2} \mathrm{DN}$ Akunga, ${ }^{2} \mathrm{P}$ Warutere. ${ }^{1} \mathrm{KONE}$ Kenya Ltd, Nairobi, Kenya; ${ }^{2}$ Department of Environmental Health, Kenyatta University, Nairobi, Kenya

\subsection{6/oemed-2018-ICOHabstracts.834}

Introduction Onshore oil drilling involves the use of heavy machinery and tools which contribute to occupational injuries. In Kenya, onshore oil drilling attracts workers from varied socio-economic backgrounds who operate in isolated locations coupled with harsh environmental conditions. Such conditions not only influence occupational hazards, but give rise to occupational injuries. The study sought to assess the occupational physical injuries among workers in onshore oil drilling operations in Turkana County, Kenya.

Methods A cross-sectional descriptive study was conducted among workers from October 2015 to February 2016. A total of 164 workers were included in the study. Convenience sampling followed by systematic random sampling were used to select the study participants. Data were collected through pretested semi-structured questionnaires. Data collected were analysed using SPSS version 20. Multivariate logistic regression analysis was used to assess the relative effect of independent variables on the outcome variable. The level of significance was set at $p<0.05$.

Results $9.8 \%$ of the workers experienced physical injuries. Duration worked in oil drilling industry $\left(\chi^{2}=11.557, d f=4\right.$ $p=0.021)$, level of education $\left(\chi^{2}=8.273, d f=3 p=0.016\right)$, hazard awareness $\left(\chi^{2}=3.655, d f=1 p=0.056\right)$, worker awareness of activities at work that pose risks of injuries $\left(\chi^{2}=7.697\right.$, $d f=1 p=0.006)$, awareness of occupational health and safety legal frameworks $\left(\chi^{2}=7.87, d f=1 p=0.005\right)$, worker participation in fire drills $\left(\chi^{2}=3.724, d f=1 p=0.054\right)$ and on job training $\left(\chi^{2}=1.359, d f=1 \quad p=0.038\right)$ were associated with occurrence of physical injuries at bivariate analysis. Age $(\mathrm{AOR}=0.354, p=0.014,95 \% \mathrm{CI}$ : 0.154 to 0.811$)$ and issues experienced while using Personal Protective Equipment (PPEs) $(\mathrm{AOR}=3.652, p=0.053,95 \% \mathrm{CI}$ : 0.984 to 13.553$)$ were significant predictors to occupational physical injuries at logistic regression.

Conclusion There is a clear interplay between risk factors; socio-demographic factors, environmental factors, and behavioural factors with occurrence of physical injuries. This could be tapped to formulate occupational health and safety specific intervention strategies for the oil and gas industry. 